\title{
Effectiveness of Structured Teaching Programme on Knowledge Regarding the Prevention of Smartphone Addiction among Nursing Students
}

\author{
Savita Pardhi ${ }^{1}$, Samiksha Satpute ${ }^{1}$, Arati Kale ${ }^{1}$, Savan Vairagade ${ }^{1}$, \\ Akshay Sadanshiv ${ }^{2}$
}

${ }^{1}$ Basic B.S.C. Nursing, Final Year Students, ${ }^{2}$ M.S.C. Nursing Lecturer (Psychiatric), Suretech College of Nursing, Nagpur, Maharashtra, India.

Corresponding Author: Akshay Sadanshiv

DOI: https://doi.org/10.52403/ijhsr.20220110

\begin{abstract}
Smartphone addiction is also known as nomophobia. (Nomophobia means a fear of being detached from mobile connectivity.) Smartphone addiction is mostly seen in students and its affects the health in both aspects physically and psychologically.

Method and Material: The study was a one group pre test and post test design (quasi experimental research design) and population for the study was GNM nursing students. The sample consists of 60 GNM nursing student. In this study, the sampling technique used was non-probability convenient sampling and the reliability of questionnaire was done by carl Pearson formula.

Results: In pre-test $23.33 \%$ of GNM nursing students were having inadequate level of knowledge score, $61.66 \%$ of GNM nursing students were having moderate level of knowledge score and only $15 \%$ of GNM nursing students were having adequate level of knowledge score. In post-test $8.33 \%$ of GNM nursing students were having inadequate level of knowledge score, 20.66\% of GNM nursing students having moderate level of knowledge score and 70\% of GNM nursing students were having adequate level of knowledge score. The pre-test mean score was found 14.60 (24.33\%) and mean score for post-test 21.65 (36.08\%).

Conclusion: The study reveals that there was deficit knowledge regarding prevention of Smartphone addiction in pre-test. The post-test knowledge was increased which reveals that structured teaching programme was effective on knowledge regarding prevention of Smartphone addiction.
\end{abstract}

Keywords: Effectiveness, Structured teaching, Knowledge, Prevention, Smartphone addiction, Nursing students

\section{INTRODUCTION}

Smartphone addiction (CPA), a widely prevalent but unspoken issue, is silently creeping into the youth of many countries. Smartphones are widely hailed for their technological benefit to mankind, the ease it creates in doing daily chores, and most of all, bridging of information as well as communication gaps among people. Rapid development of mobile phone technologies provides a rich selection of functions and improved portability that increases the prevalence of Smartphone use, especially among young people and adolescent mobile phone, especially Smartphones, are being increasingly used over recent years in both developed and developing countries. ${ }^{[1]}$

Despite offering great convenience, Smartphone can exert negative influences, induce extreme emotional changes and even cause serious physiological reactions, giving rise to the phenomenon popularly known as "Smartphone addiction". Smartphone 
facilitates young people to increase their social communication frequency, improve their relationships and make new friends. On the other hand, improper use of Smartphone influences young people negatively. Specifically, improper Smartphone use can reduce individual's concentration and the amount of information received during a typical class, block face-to-face communication, and even lead to mental or physical stress. ${ }^{[1]}$

Smartphone use electromagnetic radiation in the microwave range which may be believed harmful to health. The user cannot self-control the use of internet resulting in significant impairment at home, work, health, or interpersonal relationship. ${ }^{[2]}$

Smartphone not only has physical effects but also psychological and academicals affects or the same time, sleep deficit, anxiety, stress and depression which are all associated with excessive Smartphone use. ${ }^{[3]}$

\section{MATERIALS AND METHODS}

In present study, quantitative research approach was used. one group pretest post-test design was adopted for study. In this study, the structured teaching programme has been used as independent variables whereas knowledge regarding prevention of Smartphone addiction was considered as dependent variable by the researches to provide information. The study was conducted at Suretech College of Nursing, Nagpur. The present study was conducted among 60 GNM nursing students. non-probability convenient sampling techniques was used. Selfstructure knowledge questionnaire was prepared to assess the knowledge of nursing students regarding prevention of Smartphone addiction. To ensure the content validity of the tool, it was submitted to the tool was given to 08 experts which include one from department of Child health nursing, one from department of Community health nursing, one from Psychiatric department, two from department of obstetrics and midwifery and two from department of Medical - surgical nursing. The experts were selected based on their clinical expertise, experience and interest in the problem being studied. They were requested to give their opinion on the appropriateness and relevance of item in the tool. The reliability of the questionnaire was determined by the administration of the questions to samples. Reliability analysis was done for questionnaire by carl Pearson formula. The reliability coefficient of questionnaire was 0.9 which is more than 0.7 hence the questionnaire was found to be reliable.

\section{Inclusion Criteria:}

2nd year and 3rd year nursing students who will be,

1) Between the age group of $18-26$ year.

2) Who are willing to participate in the study.

3) Those students having Smartphone.

4) Those who are available at the time of data collection.

5) Those students who understand Hindi and English languages.

\section{Exclusion Criteria:}

2nd year and 3rd year nursing students who will be,

1) Above the age of 26 years and below the age of 18 years.

2) Who are not willing to participate in study.

3) Both boys and girls does not have Smartphone.

\section{Data Collection:}

The final study was conducted in Suretech College of Nursing, Nagpur. Data collection was done on 60 nursing students The following schedule was followed for collection.

- An objective of the study was discussed with the subject.

- Consent was obtained from the participants.

- They were assured about the confidentiality of the data. 
Savita Pardhi et.al. Effectiveness of structured teaching programme on knowledge regarding the prevention of smartphone addiction among nursing students.

- The investigator administered questionnaire as a pre-test.

- The answers were recorded immediately.

- Structured teaching programme is given immediately after pre-test.

- Post-test is taken after 7 days.

\section{STATISTICAL ANALYSIS}

The collected data was analysed by using both descriptive and inferential statistics. The data on sample characterized were described in the form of frequency and percentage. The data has been represented in the form of graphical representation whenever it was applicable. For this data was collected, validated, summarized, categorized and tabulated for the further statistical analysis.

\section{RESULT}

Presentation of data is organized in sections. SECTION A

This section deals with percentage wise distribution of nursing students of selected nursing College regarding prevention of Smartphone addiction. A convenient sample of sixty subjects was drawn from the study population who were from Suretech nursing College. The data collected obtained to describe the sample characteristics include age, gender, type of family, siblings in family, area of residence, monthly income, hobby of students, and duration of Smartphone use regarding prevention of Smartphone addiction respectively.
The following table shows the frequency and percentage distribution of demographic variables.

\begin{tabular}{|c|c|c|}
\hline \multicolumn{3}{|c|}{ Table no. - 1} \\
\hline $\begin{array}{l}\text { DEMOGHRAPHIC } \\
\text { VARIABLES } \\
\end{array}$ & FREQUENCY & PERCENTAGE \\
\hline \multicolumn{3}{|l|}{ Age (Years) } \\
\hline $18-20$ & 26 & $43.33 \%$ \\
\hline $20-22$ & 33 & $55 \%$ \\
\hline $22-24$ & 1 & $1.67 \%$ \\
\hline $24-26$ & 0 & $00 \%$ \\
\hline \multicolumn{3}{|l|}{ Gender } \\
\hline Female & 50 & $83.33 \%$ \\
\hline Male & 10 & $16.67 \%$ \\
\hline Other & 00 & $00 \%$ \\
\hline \multicolumn{3}{|l|}{ Type of family } \\
\hline Nuclear family & 49 & $81.67 \%$ \\
\hline Joint family & 11 & $18.33 \%$ \\
\hline \multicolumn{3}{|c|}{ Number of siblings in your family } \\
\hline One & 18 & $30 \%$ \\
\hline Two & 30 & $50 \%$ \\
\hline More than two & 12 & $20 \%$ \\
\hline \multicolumn{3}{|l|}{ AREA OF RESIDENCE } \\
\hline Urban & 45 & $75 \%$ \\
\hline Rural & 12 & $20 \%$ \\
\hline Slum & 03 & $05 \%$ \\
\hline \multicolumn{3}{|l|}{ Monthly income } \\
\hline Below 10000. & 09 & $15 \%$ \\
\hline $10001-20000$ & 32 & $53.34 \%$ \\
\hline $20001-30000$ & 05 & $8.33 \%$ \\
\hline Above 30000 & 14 & $23.33 \%$ \\
\hline \multicolumn{3}{|l|}{ Hobbies of students } \\
\hline $\begin{array}{l}\text { Hobby related to } \\
\text { Smartphone }\end{array}$ & 14 & $23.34 \%$ \\
\hline Cooking & 24 & $40 \%$ \\
\hline Reading a book & 05 & $08.33 \%$ \\
\hline Sports & 09 & $15 \%$ \\
\hline Other & 08 & $13.33 \%$ \\
\hline \multicolumn{3}{|c|}{ Daily uses of smartphone in 24 hours } \\
\hline Less than 2 hours & 12 & $20 \%$ \\
\hline 2-4 hours & 11 & $18.33 \%$ \\
\hline 4-6 hours & 26 & $43.34 \%$ \\
\hline More than 6 hours & 11 & $18.33 \%$ \\
\hline
\end{tabular}

\section{GRAPH}

The following graph shows the frequency and percentage distribution of demographic variables.

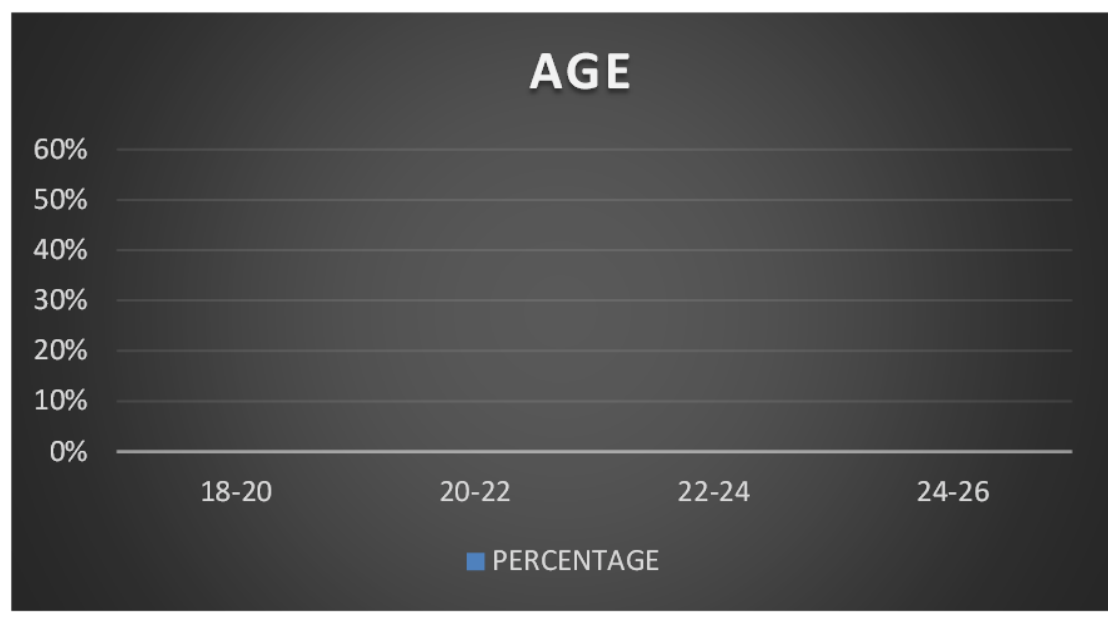

Figure No. 1. DISTRIBUTION OF GNM NURSING STUDENTS AGE. 
Savita Pardhi et.al. Effectiveness of structured teaching programme on knowledge regarding the prevention of smartphone addiction among nursing students.

The above graph showed that distribution of GNM nursing students according to their age years. $43.33 \%$ belonging to $18-20$ years. $55 \%$ in range of $20-22$ years. $1.67 \%$ in age range of $22-24$ years and $00 \%$ in age range of 24-26 years.

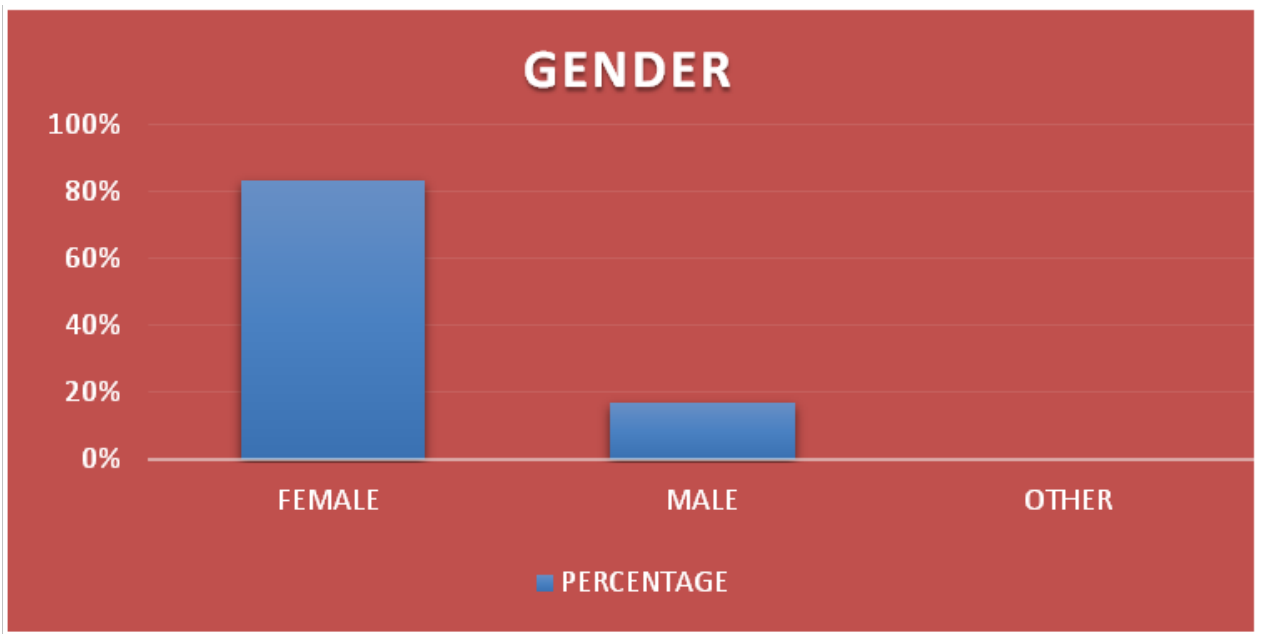

Figure No. 2. DISTRIBUTION OF GNM NURSING STUDENTS WITH REGARDS TO GENDER.

The above graph showed that frequency and percentage wise distribution of GNM nursing students with regards to gender. The genders are categorized into 3 parts. That is male, female and other, and the percentage and frequency of GNM nursing students are 50(83.33\%), $10(16.67 \%)$ and $00(00 \%)$ respectively.

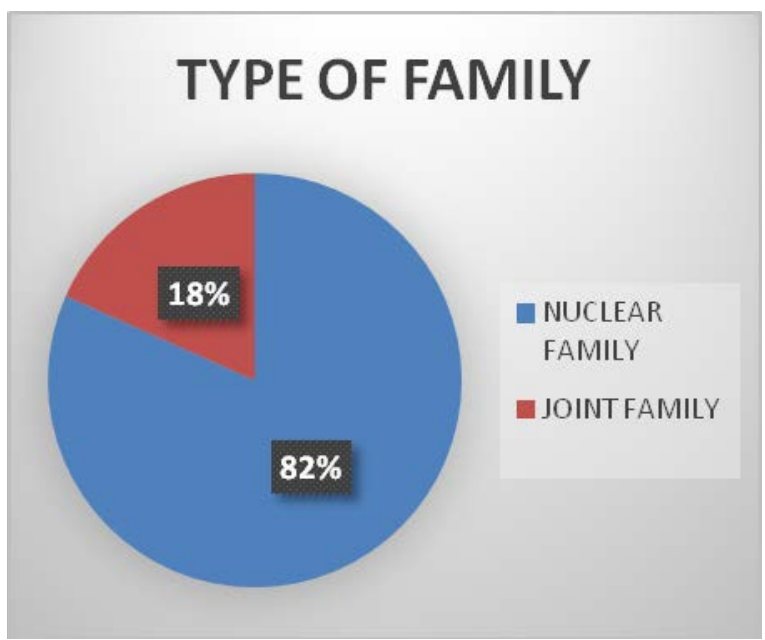

Figure No. 3. DISTRIBUTION OF GNM NURSING STUDENTS WITH REGARDS TO TYPE OF FAMILY.

The above graph showed that frequency and percentage wise distribution of GNM nursing students regard to type of family. type of family categorized into 2 type, that is nuclear family and joint family. the percentage and frequency of parents are $82 \%(49)$ and $18 \%(11)$ respectively.

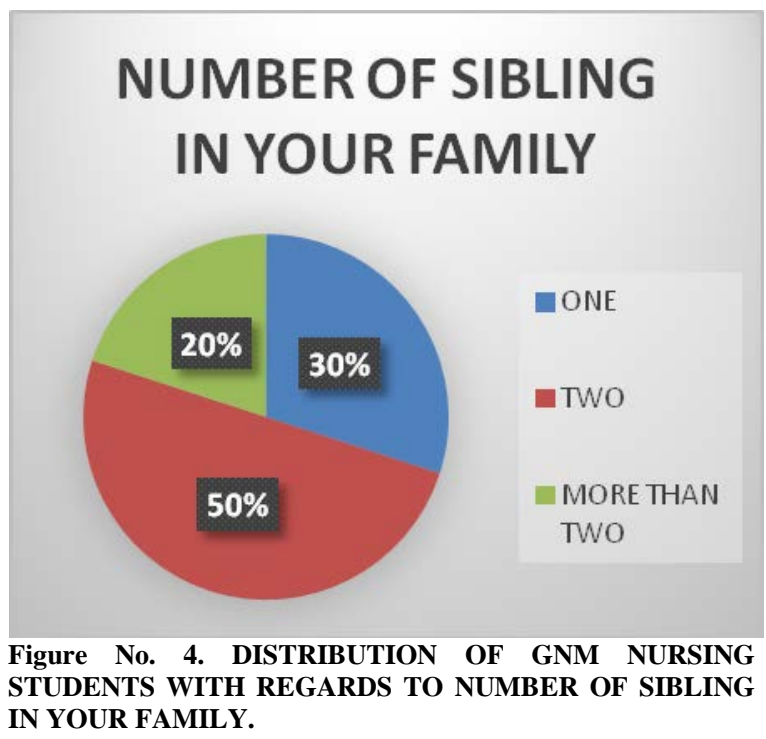

The above graph showed that frequency and percentage wise distribution of GNM nursing students with regards siblings in his/her family. one sibling in $30 \%$ family, two sibling in 50\% family and more than two siblings in $20 \%$ family. 


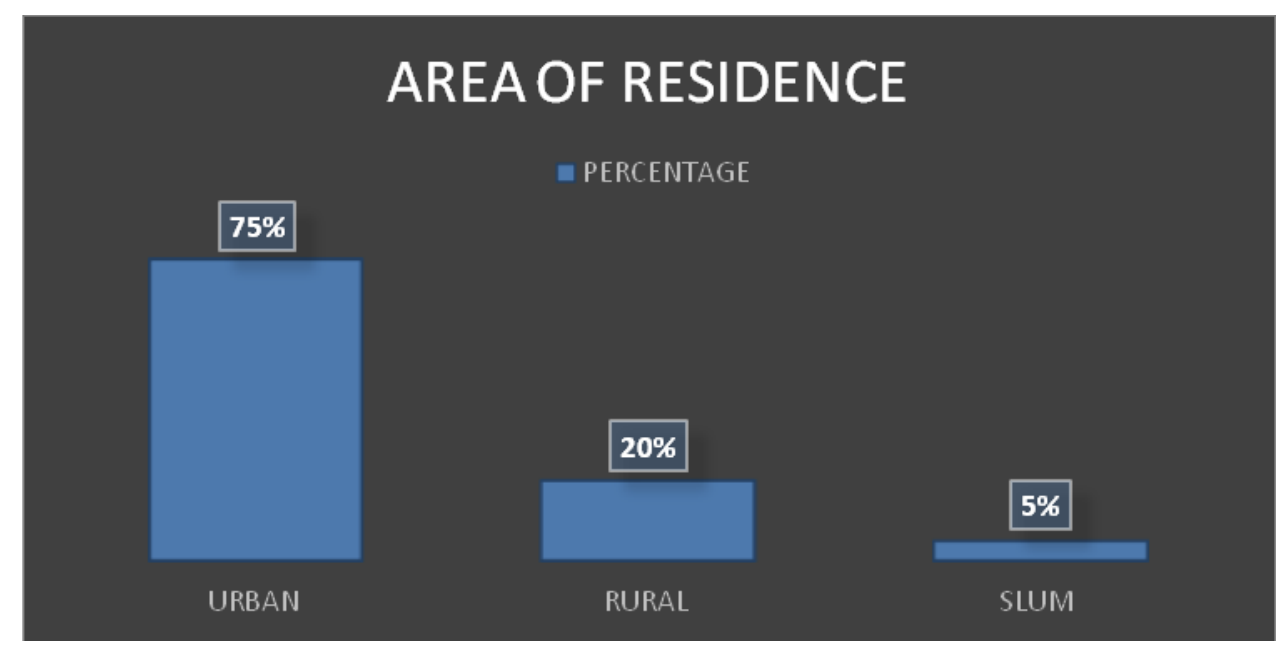

Figure No. 5. DISTRIBUTION OF GNM NURSING STUDENTS WITH REGARDS TO ARE OF RESIDENCE.

The above graph showed that frequency and percentage wise distribution of GNM nursing students with regards to area of residence in that $75 \%$ students are living in urban, $20 \%$ in ruler and $05 \%$ in slums area.

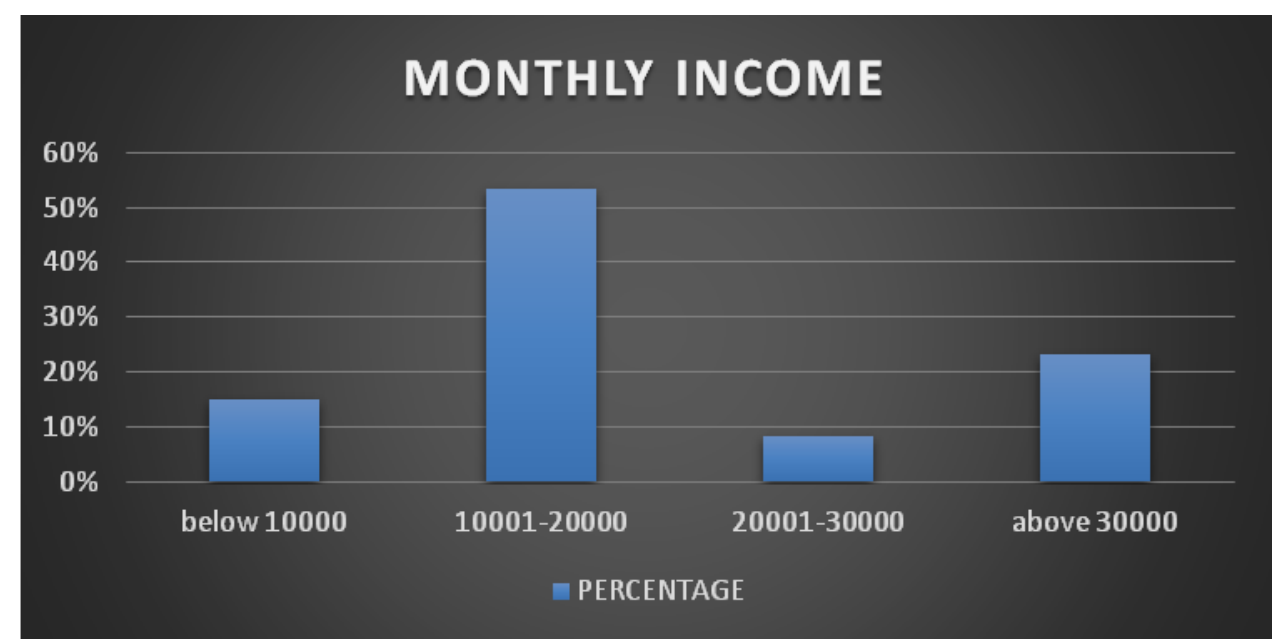

Figure No. 6. DISTRIBUTION OF GNM NURSING STUDENTS WITH REGARDS TO MONTHLY INCOME.

The above graph showed that frequency and percentage wise distribution of GNM nursing students with regards to monthly income of family the result found that below 10000 are $15 \%$, in between $10001-20000$ are $53.34 \%, 8.33 \%$ in between of $20001-30000$ and above 30000 are $23.33 \%$.

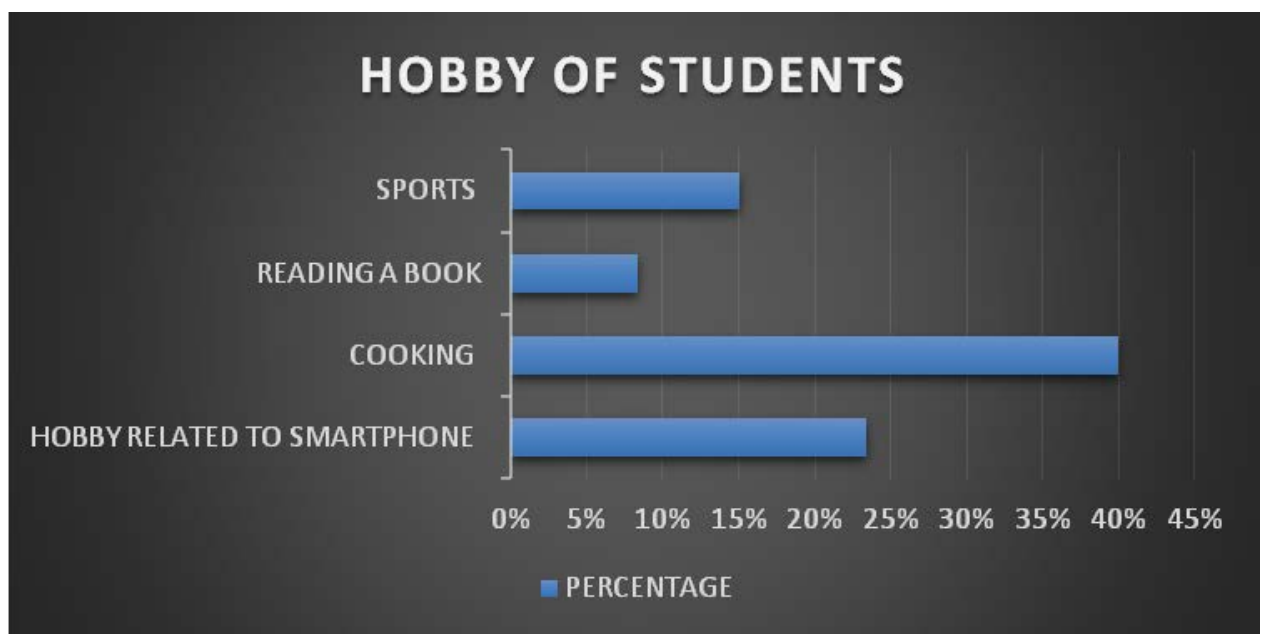

Figure No. 7. DISTRIBUTION OF GNM NURSING STUDENTS WITH REGARDS TO HOBBY OF STUDENTS. 
Savita Pardhi et.al. Effectiveness of structured teaching programme on knowledge regarding the prevention of smartphone addiction among nursing students.

The above graph showed that frequency and percentage wise distribution of GNM nursing students with regards to hobby of students, such as hobby related to Smartphone, cooking, reading a book, sports. The result was found that hobby related to Smartphone - 23.34\%, cooking $40 \%$, reading a book - $08.33 \%$, sports $15 \%$ and other-13.33\%.

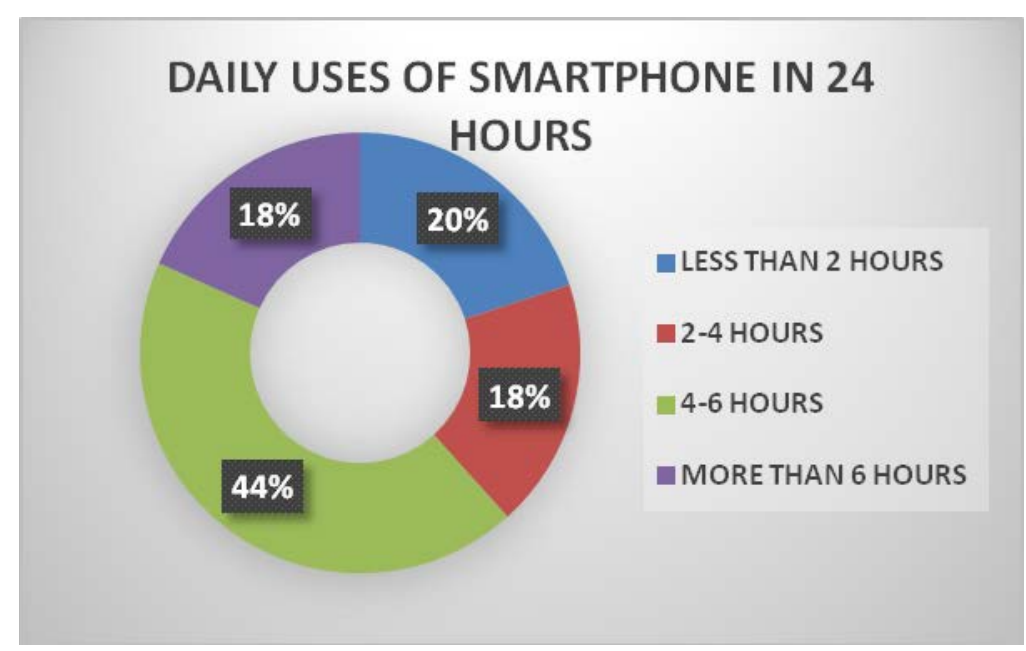

Figure No. 8. DISTRIBUTION OF GNM NURSING STUDENTS WITH REGARDS TO DAILY USES OF SMARTPHONE IN 24 HOURS.

The above graph showed that frequency and percentage wise distribution of GNM nursing students with regards to daily uses of Smartphone in 24 hours. In that $20 \%$ students are use mobile less than $2 \mathrm{hr}$. 18.33\% students use mobile in range of 2-4 hours \& 4-6 hrs. $18.33 \%$ students use mobile more than 6hrs.

\section{SECTION B}

Assessment of existing knowledge regarding prevention of smartphone addiction.

Table No. 2 - DISTRIBUTION OF NURSING STUDENTS WITH REGARDS TO PRE-TEST KNOWLEDGE REGARDING PREVENTION OF SMARTPHONE ADDICTION.

\begin{tabular}{|l|l|l|l|l|}
\hline LEVEL OF KNOWLEDGE SCORE & SCORE RANGE & PERCENTAGE SCORE & FREQUENCY & PERCENTAGE \\
\hline INADEQUATE & $0-10$ & $0-33.33 \%$ & 14 & $23.33 \%$ \\
\hline MODERATE & $11-20$ & $36.66-66.66 \%$ & 37 & $61.66 \%$ \\
\hline ADEQUATE & $21-30$ & $70-100 \%$ & 09 & $15 \%$ \\
\hline Minimum score: -02 & & & \\
Maximum score: -23 & & & \\
Mean score: -14.60 & & & \\
Mean percentage: - - 24.33\% & & & \\
\hline
\end{tabular}

The table no. 2 showed that frequency and percentage wise distribution of GNM nursing students according to pretest level knowledge on regarding prevention of Smartphone addiction. The level of knowledge were seen into 3 categories inadequate, moderate, adequate of GNM nursing students 14(23.33\%) had inadequate, 37(61.66\%) had moderate, 09(15\%) had adequate knowledge.

Table No.3- distribution of nursing students with regards to level of post test knowledge regarding smartphone addiction and its prevention

\begin{tabular}{|l|l|l|l|l|}
\hline LEVEL OF KNOWLEDGE SCORE & SCORE RANGE & PERCENTAGE SCORE & FREQUENCY & PERCENTAGE \\
\hline INADEQUATE & $0-10$ & $0-33.33 \%$ & 05 & $8.33 \%$ \\
\hline MODERATE & $11-20$ & $36.66-66.66 \%$ & 13 & $20.66 \%$ \\
\hline ADEQUATE & $21-30$ & $70-100 \%$ & 42 & $70 \%$ \\
\hline Minimum score: - 08 & & & \\
Maximum score: - 27 & & & \\
Mean score: - 21.65 & & & \\
Mean percentage: - 36.08\% & & & \\
\hline
\end{tabular}


Savita Pardhi et.al. Effectiveness of structured teaching programme on knowledge regarding the prevention of smartphone addiction among nursing students.

The table no. 3 showed that frequency and percentage wise distribution of GNM nursing students according to posttest level knowledge on regarding prevention of Smartphone addiction. The level of knowledge was seen into 3 categories inadequate, moderate, adequate of GNM nursing students 05(8.33\%) had inadequate, $13(21.66 \%)$ had moderate, 42(70\%) had adequate knowledge.

\section{SECTION C \\ Analysis of effectiveness of structured teaching programme on knowledge regarding prevention of smartphone addiction}

Table No. 4 - Significant difference between knowledge score in pre and post-test of nursing students on knowledge regarding prevention of Smartphone addiction

\begin{tabular}{|l|l|l|l|l|l|l|l|}
\hline Overall & Mean & Standard deviation & Mean percentage & t- value (Calculated) & p-value & t-value (Tabulated) & Significance \\
\hline Pre test & 14.60 & 6.27 & $24.33 \%$ & 14.02 & $\mathrm{P}<0.05$ & 2001 & \\
\cline { 1 - 3 } Post test & 21.65 & 6.45 & $36.08 \%$ & & & &
\end{tabular}

The above table revealed that mean value for pre-test was 14.60 and for post-test was 21.65. The standard deviation for the pre-test was 6.27 and for the post test was 6.45. The mean percentage for the pre-test was $24.33 \%$ and for post-test was $36.08 \%$. The t-value for the above table was calculated as 14.02 and $p$ value was less than 0.05 .

Hence it is statistically interpreted that structured teaching programme on knowledge regarding prevention of Smartphone addiction was effective. Thus, $\mathrm{H} 1$ is accepted and $\mathrm{H} 0$ is rejected.

\section{SECTION D}

The analysis of data related to association of knowledge among nursing students of selected nursing College in Nagpur city in relation to demographic variables. It was calculated with the help of chi square test.

TABLE NO. 5 - An analysis of data to find association between post-test knowledge and selected demographic variables

\begin{tabular}{|c|c|c|c|c|c|c|}
\hline $\begin{array}{l}\text { SR. } \\
\text { NO. }\end{array}$ & $\begin{array}{l}\text { DEMOGRAPHIC } \\
\text { VARIABLE }\end{array}$ & $\begin{array}{l}\text { Chi-Square } \\
\text { VALUE }\end{array}$ & $\begin{array}{l}\text { DEGREE OF } \\
\text { FREEDOM }\end{array}$ & $\begin{array}{l}\text { TABLE } \\
\text { VALUE }\end{array}$ & $\begin{array}{l}\text { LEVEL OF } \\
\text { SIGNIFICANCE }\end{array}$ & SIGNIFICANCE \\
\hline 1. & $\mathrm{AGE}$ & 1.71 & 6 & 12.59 & 0.05 & NOT SIGNIFICANT \\
\hline 2. & GENDER & 2.6 & 4 & 9.49 & 0.05 & NOT SIGNIFICANT \\
\hline 3. & TYPE OF FAMILY & 1.31 & 2 & 5.99 & 0.05 & NOT SIGNIFICANT \\
\hline 4. & NUMBER OF SIBLINGS & 5.49 & 4 & 9.49 & 0.05 & NOT SIGNIFICANT \\
\hline 5. & AREA OF RESIDENCE & 6.90 & 4 & 9.49 & 0.05 & NOT SIGNIFICANT \\
\hline 6. & MONTHLY INCOME & 0.65 & 6 & 12.59 & 0.05 & NOT SIGNIFICANT \\
\hline 7. & HOBBY OF STUDENT & 8.98 & 8 & 15.51 & 0.05 & NOT SIGNIFICANT \\
\hline 8. & $\begin{array}{lcc}\text { DAILY } & \text { USES } & \text { OF } \\
\text { SMARTPHONE IN } 24 \text { HR. }\end{array}$ & 4.33 & 6 & 12.59 & 0.05 & NOT SIGNIFICANT \\
\hline
\end{tabular}

\section{DISCUSSION}

The Smartphone today is a lifeline for many. It is estimated that around 4.5 billion people use the Smartphone worldwide. And it comes as no surprise that a huge chunk of this quantity consists of the youth. The Smartphone is more of a necessity for them than a luxury. Umpteen number of surveys conducted on the youth worldwide have figured out that they consider Smartphone an integral part of survival and some have even gone to the extent of saying that they would rather go without food for a day than without their Smartphones. With constant texting, calling, listening to music, playing phone games or simply fiddling with the phone being such an integral part of their lifestyles, it is little wonder that not having it around strikes them with paranoia. To improve the knowledge regarding the prevention of Smartphone addiction in adolescent and it will be helpful to reduce the health hazards which are caused by excessive use of Mobile phone. Overuse of Smartphone can result in number of health hazards such as eye strain, sleep disturbance, depression, anxiety, headache, increase loneliness and stress. These are all factors tremendously responsible for poor health performance. 
Savita Pardhi et.al. Effectiveness of structured teaching programme on knowledge regarding the prevention of smartphone addiction among nursing students.

The present study focuses on the knowledge of nursing students on prevention of Smartphone addiction. For that 60 nursing students selected for the study. In the pre-test $15 \%$ students have adequate knowledge and post- test knowledge of students $70 \%$ on prevention of Smartphone addiction. Other studies were conducted on Prevalence of smartphone addiction. The prevalence of Wardha, Sawangi students was found to be $24.64 \% .{ }^{[4]}$ In Korean middle school students was 30.9 percent. It is a very high rate compared with that reported in other countries. $^{[5]}$

On the basis of the findings of the study, it is recommended that a similar study can be conducted on a large scale including general population across the country can be carried out in order to estimate the level of knowledge regarding prevention of Smartphone addiction. and descriptive study can be undertaken with government project to help students regarding preventive measures of Smartphone addiction.

\section{CONCLUSION}

The nursing students do not have adequate knowledge regarding prevention of Smartphone addiction in pre-test. There is a significant increase in knowledge of students after the structured teaching programme. To find the effectiveness of structured teaching programme ' $t$ ' test was applied and t value was calculated, post-test knowledge score was significantly higher at 0.05 level than that of pre-test score. Thus, it was concluded that seem on knowledge regarding the prevention of Smartphone addiction found effective as a teaching strategy. Demographic variables did not show a major role in influencing knowledge score among nursing students.

Acknowledgement: None

\section{Conflict of Interest: None}

\section{Source of Funding: None}

\section{Ethical Approval: Approved}

\section{REFERENCES}

1. Reddy N, Kiran S, Sanjana JS. Mobile phone addiction: Symptoms, impacts and causes - A review. ICIVBS. 2018; 81-86.

2. Bala R, Anchal S, Kaur S, et al. A descriptive study to assess the knowledge of nursing students: regarding mobile and internet addiction. Int $\mathrm{J}$ Adv Res Community Health Nurs. 2020; 2(1)17-21.

3. Sehar S. Cell phone addiction and physiological health in adolescents. EXCLI J. 2019; 18:47-50.

4. Jain P, Gedam S, Patil P. Study of Smartphone: prevalence, pattern of use, and personality dimensions among medical students. Open J Psy. \& Allied S. 2019 June; 10(2):132.

5. Cha S, Seo B. Smartphone use and Smartphone addiction in middle school: Prevalence, social networking service, and game use. Health Psychol Open. 2018 Feb; 5(1):205-305.

How to cite this article: Pardhi S, Satpute S, Kale A et.al. Effectiveness of structured teaching programme on knowledge regarding the prevention of smartphone addiction among nursing students. Int $J$ Health Sci Res. 2022; 12(1): 70-77. DOI: https://doi.org/10.52403/ ijhsr.20220110 